\title{
"AN EMPIRICAL STUDY ON OCCUPATIONAL STRESS IN WOMEN ACADEMACIANS AT WORKPLACE".
}

\author{
${ }^{1}$ Ms. Nandini Pandey \\ ${ }^{2}$ Dr. Kesava Rao
}

\section{INTRODUCTION}

\section{Stress in Higher Education}

Although high level of stress has been observed in teachers generally, the higher education sector is a relatively new focus of concern. It has been recognized that organizational change can be the significant cause of occupational stress. Over the past 10 - 20 years, our Indian Higher Education has undergone a more profound reorientation than any other system. The most obvious symptom of change in the sector has been the move towards mass higher education. There has not been corresponding increase in the numbers of academic teaching and support staff. Student staff ratio is now 15:1. There are a lot of colleges coming up. But the pay of the teaching staff member is not up to the mark and Administrative workload is more for the teaching staff members. The widespread changes in the policy and practices have led to a significant increase in workload and job related pressures for many academic staff. This has not been accompanied by a corresponding increase in human and technical resources.

\section{STRESS AMONG WORKING WOMEN}

India and its society have drastically changed in the past few years. The roles of women have drastically changed and today women have joined hands with men as a part of the workforce in the organization.
The consequence is that women live in two systems and need to perform both familial as well as professional roles. Hence, a lot of stress on the modern women.

Attempts have been made to trace the particular stresses, which are dominant among working women in the past. Various behavioral experts like, R Kapur (1969), Surti (1982), Tharakan (1992), Pareek and Mehta (1997) and S Mathur, have conducted various studies on the factors leading to stress in working women.

\section{STRESS AMONG WOMEN ACADEMICIANS}

Academics is a field which is very demanding and tricky, in the sense that it involves handling of people, handling their emotions, feelings, cultures, ideas, etc. A lot of work has been done on stress among women academicians. The physical and mental health of the academicians is very important as it affects the target group, who are the students. The teaching profession is one of the human service professions, which can be quite stressful.

Stress is a dynamic condition in which an individual is confronted with an oppurtunity, demand or resource related to what the individual desires and for which the outcome is perceived to be both uncertain and important.

Stress in an individual can arise due to various factors like:

1 Ms. Nandini Pandey, Research Scholar, Dayananda Sagar College of Engineering, Bangalore

Email: nandinimail@gmail.com, Phone: 9611344765

2 Dr. Kesava Rao RNS INSTITUTE OF TECHNOLOGY, BANGALORE 
1. Environmental Factors - these are factors which are outside to the individual and the organisation in which he is employed. Could be factors like technological changes, political changes, labour laws so on and so forth.

2. Organisational Factors - these are the factors which are present in the organisation. Could be factors like task demands, role demands, or interpersonal demands.

3. Personal Factors - these factors are family issues, personal economic problems and inherent personality charecteristics which are unique to the individual.

Research is any organised inquiry carried out to provide information for solving problems. Business research is a systematic inquiry that provides information to guide business decisions. This includes reporting, descriptive, explanatory and predictive studies.

\section{REVIEW OF LITERATURE ON DEFINITION OF STRESS}

Various researchers have conducted around the world a lot of studies to understand the concept of "STRESS" in humans have conducted a lot of studies. A following are a few of them, which basically aim to explain and understand the meaning stress, as human phenomena.

The ancient Indian scholars who all related to the concept of present day Stress developed a number of concepts.

1. Palsane, 1993, has discussed that the Indian tradition is characterized by a holistic approach to the human phenomena. It is said that behaviour is characterized by the body mind relationship of human beings.

2. SKR Rao, 1983, traces the origin of stress in the Indian thought to two Sanskrit words, "Klesa" and"Dukha", which mean 'Pain" or "torment".

3. Surti, 1982, studied the psychological correlation of role stress in women academicians. The author concluded that there is minimum role stress among women academicians as the job is considered prestigious, working hours are short, vacations are frequent and pay scales are reasonable.

4. Jamuna \& Ushashre, 1990, carried out a study to understand the burnout among women in teaching profession. The results indicated that women in the lower age group and those working in private institutions exhibit a higher degree of burnout.

5. Topper (2007) defines stress as a person's psychological and physiological response to the perception of demand and challenge.

6. Rees and Redfern (2000) assert that there is no universally accepted definition of the term stress.

7. Ornelas and Kleiner (2003) argue that stress is the by-product of modern life that results from our efforts of trying to balance the demands of the workplace and of family life.

8. Tehrani (2002) argued that stress is caused by unsympathetic organizational culture, poor communication between managers and employees, lack of involvement in decisionmaking, bullying and harassment, continual or sudden change, insufficient resources, conflicting priorities, and lack of challenges.

9. The concept of stress was first introduced in the life sciences by HANS SEYLE in 1936. it is a concept borrowed from the natural sciences. Derieved from the Latin word, "STRINGERE", stress was popularly used in the $17^{\text {th }}$ century to mean hardship, strain, adversity or affliction. It was used in the $18^{\text {th }}$ and $19^{\text {th }}$ centuries to denote pressure, strain or strong effort with reference to an object or person.

10.Pradhan and Mishra, 1995, examined gender differences in life stress burnout and the life stress. The study revealed that there are significant gender differences in the feeling of lack of personal accomplishment, both with regard to 
frequency and intensity of stress. They also found that there were significant gender differences in the intensity of life stress. They also found that there is a significant relationship between Emotional Exhaustion and life stress in women.

11. Ram, 1998, conducted a study on stress in working mothers and found that there is a highly significant and positive relationship between the factors.

\section{RESEARCH DESIGN}

It is an outline of the research process from stating the hypothesis and its operational implications to the final analysis of the data along with appropriate interpretations.

\section{STATEMENT OF THE PROBLEM}

\section{"ASTUDY ON THE LEVEL OF STRESS IN WOMEN ACADEMECIANS AT THE WORKPLACE”.}

This study has been conducted on the women employees of a leading eductaional institution at Bangalore. Therefore, with reference to the above context the collected data has been analysed and interpreted accordingly.

\section{OBJECTIVES OF THE STUDY}

1. To identify the stress causing factors among the women employees.

2. To understand the relationship between stress and employee age and designation,

3. To understand the relationship between stress and employee recoginition

\section{SCOPE OF THE STUDY}

The study was conducted on the women employees (academecians) of Dayanda Sagar Institutions, Bangalore.

\section{TYPE OF RESEARCH}

This particular research study is an exploratory research study which is qualitative in nature, emphasizing survey method. For this particular study, psychometric test has been administered on the sample using a structured questionnaire to analyse various factors like stress levels, designation, quality of work, distance from home etc

\section{RESEARCH HYPOTHESIS}

It is a scientific method of testing a predicted or hypothesised relationship among variables. The research hypothesis is a predictive statement that relates an independent variable to a dependent variable. Usually a research hypothesis must contain atleast one independent and one dependent variable.

Following three hypotheses have been tested:

1. Stress and Age.

2. Stress and Designation.

3. Stress and Recognition.

\section{SAMPLE}

The samples are the women academicians at a leading educational institution at Bangalore. The population size is 150 (approx 150 women academicians work in the organization).

\section{SAMPLING PROCEDURE}

For this particular study, non probability sampling procedure is applied in which judgement sampling technique is used for selecting items which the researcher considers as representative of the population. This technique is usually used in qualitative research. The sampling error cannot be estimated and hence sampling bias is present.

\section{DATA COLLECTION}

The task of data collection begins after a research problem has been defined and a research design has been chalked out. For this particular study, a psychometric test has been administered and the data is collected with the help of a questionnaire. The questionnaire is a combination of structured, non structured, open ended and closed ended questions from which the respondents have to choose.

ANALYSIS AND PROCESSING OF DATA 
The collected data has to be analysed and processed in accordance with the outline laid down for the purpose at the time of developing the research design. For this particular study, the collected data is analysed using chi square test.

\section{GEOGRAPHICAL COVERAGE}

The study was restricted to Bangalore only.

\section{LIMITATIONS}

- The study was restricted to the women academician at a single eductional institution.

- The sample size was only 80 , which is not a true representation of the population as a whole.

- Ignorance and lack of co - operation of the respondents.

- Time constraint.

\section{DATA ANALYSIS AND INTERPRETATION}

\section{Hypothesis Testing}

In probability theory and statistics, the chi-square distribution is one of the most widely used theoretical probability distributions in inferential statistics, e.g., in statistical significance tests. It is useful because, under reasonable assumptions, easily calculated quantities can be proven to have distributions that approximate to the chi-square distribution if the null hypothesis is true. The formula for computing chi square is given below:

Chi Square $=$ " $[($ Observed Frequency - Expected Frequency) ${ }^{2}$ / Expected Frequency]

Where Expected Frequency $=\left(\right.$ Row Total ${ }^{*}$ Column Total) / Grand Total

\section{Rules}

1. If the calculated value is greater than table (critical) value, the null hypothesis is rejected

2. If the calculated value is less than or equal to table (critical) value, the null hypothesis is accepted

For conducting test of independence (chi square based), following classification has been used for Question 13: I find my job is stressful

YES: Strongly Agree, Agree, and Neither Agree or Disagree

NO: Disagree, and Strongly Disagree

Following three hypotheses have been tested:

1. Stress and Age.

2. Stress and Designation.

3. Stress and Recognition.

1. Stress (Question 13) and Age

Step 1: Null and Alternate Hypothesis

Null Hypothesis $(\mathrm{H} 0)$ : There is no relationship between Age and Stress

Alternate Hypothesis ( $\mathrm{H} 1)$ : There is relationship between Age and Stress

Step 2: Statistical Test - Chi Square is appropriate as data type is nominal (categorical)

Step 3: Significance Level $(a)=0.05$. Degrees of freedom $=($ rows -1$) *($ columns -1$)=1$

Step 4: Chi Square Computation

Table 1: Actual Frequency of Stress and Age group

\begin{tabular}{|l|c|c|c|}
\hline \multirow{2}{*}{ Actual Frequency } & \multicolumn{2}{|c|}{ I find my job is stressful (Question 13) } & \multirow{2}{*}{ TOTAL } \\
\cline { 2 - 3 } & Yes & No & 41 \\
\hline Age $(<=30 \mathrm{yrs})$ & 22 & 19 & 40 \\
\hline Age $(>30 \mathrm{yrs})$ & 18 & 22 & 81 \\
\hline TOTAL & 40 & 41 & \multirow{2}{*}{} \\
\hline
\end{tabular}


Table 2: Computation of Chi Square

\begin{tabular}{|l|c|c|c|c|}
\hline Observed (O) & Expected $(E)$ & O-E & $(\mathbf{O}-\mathrm{E})^{*}(\mathrm{O}-\mathrm{E})$ & $(\mathrm{O}-\mathrm{E}) *(\mathrm{O}-\mathrm{E}) / \mathrm{E}$ \\
\hline 22 & 20.2 & 1.8 & 3.1 & 0.2 \\
\hline 18 & 19.8 & -1.8 & 3.1 & 0.2 \\
\hline 19 & 20.8 & -1.8 & 3.1 & 0.1 \\
\hline 22 & 20.2 & 1.8 & 3.1 & 0.2 \\
\hline & & & SUM & 0.6 \\
\hline
\end{tabular}

Table 3: Actual Frequency of Stress and Designation

\begin{tabular}{|l|l|c|c|c|}
\hline \multirow{2}{*}{ Actual Frequency } & \multirow{2}{*}{} & \multicolumn{2}{|c|}{ I find my job is stressful (Question 13) } & \multirow{2}{*}{ GRAND TOTAL } \\
\cline { 3 - 5 } & & Yes & No & 66 \\
\hline Designation & Asst Prof/Prof/HOD & 38 & 28 & 15 \\
\hline & Lecturer / Sr Lecturer & 2 & 13 & 81 \\
\hline & Grand Total & 40 & 41 & \multirow{2}{*}{8} \\
& & &
\end{tabular}

Chi Square Calculated Value $=0.6$

Step 5: Table Value at a 0.05 and degrees of freedom 1 is 3.84

Step 6: Interpretation

Since the calculated value (0.6) is less than the table value (3.84), the alternate hypothesis is rejected. Hence we conclude that there is no relationship between Age and Stress

\section{Stress (Question 13) and Designation}

Step 1: Null and Alternate Hypothesis

Null Hypothesis $(\mathrm{HO})$ : There is no relationship between Designation and Stress

Alternate Hypothesis ( $\mathrm{H} 1)$ : There is relationship between Designation and Stress

Step 2: Statistical Test - Chi Square is appropriate as data type is nominal (categorical)

Step 3: Significance Level $(a)=0.05$. Degrees of freedom $=($ rows -1$) *($ columns -1$)=1$

Step 4: Chi Square Computation

Chi Square Calculated Value $=9.6$

Step 5: Table Value at a 0.05 and degrees of freedom 1 is 3.84

Step 6: Interpretation

Since the calculated value (9.6) is greater than the table value (3.84), the null hypothesis is rejected. Hence we conclude that there is a relationship between Designation and Stress

3. Stress (Question 13) and Recognition (Question 23)

Step 1: Null and Alternate Hypothesis

Null Hypothesis $(\mathrm{H} 0)$ : There is no relationship between Recognition and Stress

Alternate Hypothesis ( $\mathrm{H} 1)$ : There is relationship between Recognition and Stress 
Table 4: Computation of Chi Square

\begin{tabular}{|l|c|c|c|c|}
\hline Observed (O) & Expected (E) & O-E & $(\mathbf{O}-\mathrm{E})^{*}(\mathbf{O}-\mathrm{E})$ & $(\mathbf{O}-\mathrm{E})^{*}(\mathbf{O}-\mathrm{E}) / \mathbf{E}$ \\
\hline 38 & 32.6 & 5.4 & 29.2 & 0.9 \\
\hline 2 & 7.4 & -5.4 & 29.2 & 3.9 \\
\hline 28 & 33.4 & -5.4 & 29.2 & 0.9 \\
\hline 13 & 7.6 & 5.4 & 29.2 & 3.9 \\
\hline & & & SUM & 9.6 \\
\hline
\end{tabular}

Table5: Actual Frequency of Stress Vs Recognition.

\begin{tabular}{|l|l|c|c|c|}
\hline \multirow{2}{*}{ Actual Frequency } & & \multicolumn{2}{|c|}{ I find my job is stressful (Question 13) } & \multirow{2}{*}{} \\
\cline { 3 - 5 } & & Yes & No & GRAND TOTAL \\
\hline My efforts at job is & & 31 & 18 & 49 \\
recognized (Question 23) & Yes & 9 & 23 & 32 \\
& No & 40 & 41 & 81 \\
\hline
\end{tabular}

Table 6: Chi Square Computation.

\begin{tabular}{|l|c|c|c|c|}
\hline Observed (O) & Expected (E) & O-E & $(\mathbf{O}-\mathrm{E})^{*}(\mathrm{O}-\mathrm{E})$ & $(\mathrm{O}-\mathrm{E})^{*}(\mathrm{O}-\mathrm{E}) / \mathrm{E}$ \\
\hline 31 & 24.2 & 6.8 & 46.3 & 1.9 \\
\hline 9 & 15.8 & -6.8 & 46.3 & 2.9 \\
\hline 18 & 24.8 & -6.8 & 46.3 & 1.9 \\
\hline 23 & 16.2 & 6.8 & 46.3 & 2.9 \\
\hline & & & SUM & 9.6 \\
\hline
\end{tabular}

Step 2: Statistical Test - Chi Square is appropriate as data type is nominal (categorical)

Step 3: Significance Level $(a)=0.05$. Degrees of freedom $=($ rows -1$){ }^{*}($ columns -1$)=1$

Step 4: Chi Square Computation

Chi Square Calculated Value $=9.6$
Step 5: Table Value at a 0.05 and degrees of freedom 1 is 3.84

Step 6: Interpretation

Since the calculated value (9.6) is greater than the table value (3.84), the null hypothesis is rejected. Hence we conclude that there is a relationship between Recognition and Stress. 


\section{SUGGESTIONS}

2o Systems should be put in place where the efforts of people are recognized and achievers are rewarded.

$\therefore$ A holistic approach has to be incorporated to overcome the stress factors observed in the employees i.e., introduction of meditation programmes, yoga sessions, setting up in-house gyms, making it compulsory for the employees to participate in various kinds of training programmes especially stress handling techniques will help the employees to lead a stress free life.

2o A day in a week can be reserved, as a day for working informally which would act as a de stressor and in turn would increase the motivation and interest among the employees.

$\curvearrowright$ The organization can also try to reduce job stress by bringing in a consultant to recommend ways to improve working conditions. Involves the identification of stressful aspects of work (e.g., excessive workload, conflicting expectations, appraisal, recognition) and the design of strategies to reduce or eliminate the identified stressors.

\section{CONCLUSION}

From the study it was found that stress is a very vital component of organizational effectiveness and performance of the employees. It was found that factors like recognition and designation does add stress if not provided to the female academicians. Hence the organizations has to concentrate on these factors to keep the employees motivated and stress free.

\section{Bibliography}

\section{References}

1. Aaron, M., (2006) - Dashboards in Your Future [Electronic] Interactions Magazine January/February 2006.

2. Bryan, A \& Bell, E (2003) Business Research Methods, Oxford University Press, 2003.

3. Classe, A. (1999), "Performance anxiety", Accountancy, Vol. 123.

4. Daft, L. R, (2004) - Organization Theory and Design ( $8^{\text {th }}$ edition). Donnelly \& Sons Company, Willard, $\mathrm{OH}$. 